\title{
Níveis de cálcio em dietas para poedeiras semipesadas após o pico de postura ${ }^{1}$
}

\section{Fernando Guilherme Perazzo Costa ${ }^{2}$, Cleber Franklin Santos de Oliveira ${ }^{3}$, Leilane Rocha Barros Dourado ${ }^{4}$, Raul da Cunha Lima Neto ${ }^{5}$, Miguel Ângelo da Silva Fernandes Campos ${ }^{3}$, Anny Graycy Vasconcelos de Oliveira Lima ${ }^{3}$}

\author{
1 Projeto de PIBIC/UFPB/CNPq do segundo autor. \\ ${ }^{2}$ Departamento de Zootecnia da UFPB, Areia-PB, CEP: 58397-000. \\ ${ }^{3}$ Curso de Zootecnia da UFPB. \\ 4 Programa de Pós-Graduação - FCAVIUNESP. \\ ${ }^{5}$ Programa de Pós-Graduação em Zootecnia da UFPB.
}

RESUMO - Um experimento foi conduzido com o objetivo de estudar os efeitos dos níveis de cálcio nas rações sobre o desempenho e a qualidade de ovos de poedeiras comerciais. Foram utilizadas 216 poedeiras da linhagem Lohmann Brown no período de 39 a 55 semanas de idade. O delineamento utilizado foi inteiramente casualizado, composto de seis níveis de cálcio $(3,0 ; 3,4 ; 3,8 ; 4,2 ; 4,6 ; 5,0 \%)$ e seis repetições de seis aves por parcela. Os níveis de cálcio avaliados não influenciaram os parâmetros produtivos, mas afetaram significativamente as porcentagens de albúmen e casca do ovo. O aumento do cálcio na dieta promove incremento na qualidade da casca do ovo em relação aos demais componentes do ovo. Recomenda-se nível de 4,3\% de cálcio em dietas para poedeiras semipesadas após o pico de postura.

Palavras-chave: exigência, produção de ovos, qualidade da casca

\section{Levels of calcium in diets for brown layers post-peak production}

\begin{abstract}
Two hundred and sixteen layers were raised from 39 to 55 weeks of age to study the effects of levels of calcium in the rations on performance and eggs quality of brown commercial layers. A completely randomized experimental design were used with six levels of calcium (3.0; 3.4; 3.8; 4.2; 4.6 and 5.0\%) and six replicates of six layers hens. There was no effect of calcium levels on hen performance, however significantly affected the percentage of albumen and egg shell. The increase of calcium in the diet promoted increment in egg shell quality in relationship to other eggs components. The calcium level of $4.3 \%$ is recommended for brown layer hens after production peak.
\end{abstract}

Key Words: eggs production, egg shell quality, requirements

\section{Introdução}

Galinhas poedeiras modernas são muito sensíveis às variações dos níveis nutricionais da dieta. Em estudos com essas aves, o que se busca é maior produção de ovos, boa conversão alimentar e menor porcentagem de ovos defeituosos. A suplementação mineral pode ser uma alternativa para melhorar o desempenho destas aves e da casca dos ovos.

Em virtude dos avanços no melhoramento genético, na nutrição, nos fatores de ambiência e no manejo, que resultam em maior eficiência de produção, torna-se necessária revisão periódica das exigências de cálcio para poedeiras, uma vez que este mineral é fundamental para o desenvolvimento ósseo durante a fase de crescimento da ave e para formação da casca do ovo durante a fase de postura e ainda participa nos processos metabólicos. Estudos dessa natureza têm repercussão nos aspectos econômicos das rações e contribuem para minimizar os custos de produção e reduzir possíveis impactos no meio ambiente. De acordo com Hunton (2004), qualquer defeito na casca pode comprometer o valor do ovo tanto para a produção de pintos de 1 dia como para a utilização na alimentação.

A suplementação de macrominerais em rações para aves tem sofrido modificações, não somente em razão do melhoramento genético mas também em virtude da evolução das pesquisas, que têm demonstrado a necessidade do conhecimento das características físicas e químicas das fontes de cálcio, cuja biodisponibilidade deve ser considerada. Em rações para aves e suínos, a suplementação 
dos macrominerais representa de 3 a $4 \%$ do custo das rações e a do microminerais, de 0,4 a 0,6\% (Bertechini, 1998).

Segundo Leeson \& Summers (1979), as poedeiras são capazes de ajustar a ingestão de cálcio necessária para a formação da casca dos ovos de acordo com suas necessidades. O excesso de ingestão de cálcio nem sempre têm resultados positivos, pois pode comprometer o consumo de ração e a produção de ovos (Scott et al., 1982).

Bar et al. (2002) reportaram que teores entre 3,6 a 4,0\% de cálcio na dieta são suficientes para boa produção de ovos e maior qualidade da casca em poedeiras semipesadas de 57 a 92 semanas de idade. Rodrigues et al. (2005) recomendam 3,5\% de cálcio em dietas para poedeiras leves de segundo ciclo. Em experimento com poedeiras brancas de 79 a 106 semanas de idade, Hernández-Sánchez et al. (2006) verificaram maior espessura de casca de ovo quando o consumo diário de cálcio foi de 4,02 g/ave, porém, recomendaram 3,17 g/ave/dia como nível econômico ótimo.

Este trabalho foi realizado com o objetivo de verificar os efeitos de níveis de cálcio em dietas para poedeiras semipesadas após o pico de postura sobre as características de desempenho e qualidade dos ovos.

\section{Material e Métodos}

O experimento foi realizado no Setor de Avicultura do Departamento de Zootecnia do Centro de Ciências Agrárias da Universidade Federal da Paraíba. O período experimental foi de 112 dias, divididos em quatro períodos de 28 dias. Foram utilizadas 216 poedeiras comerciais da Linhagem Lohmann Brown com peso inicial de 2.001,9 g, alojadas em galpão convencional de postura com comedouros tipo calha e bebedouros do tipo nipple. Antes do período inicial do experimento, as aves foram pesadas para padronização dos pesos de cada parcela e passaram por um período de adaptação à ração experimental (uma semana).

O programa de iluminação adotado foi de 17 horas (natural + artificial) de luz por dia e as rações experimentais e a água foram fornecidas ad libitum. As rações foram formuladas à base de milho e farelo de soja e suplementadas com vitaminas e minerais, segundo recomendações de Rostagno et al (2000), exceto quanto aos níveis de cálcio (Tabela 1).

Os ovos foram coletados duas vezes ao dia, às 10 e 16 h, e os dados como freqüência de postura, número de ovos íntegros, de ovos quebrados, trincados, com casca fina,

Tabela 1 - Composição das rações experimentais

\begin{tabular}{|c|c|c|c|c|c|c|}
\hline \multirow[t]{2}{*}{ Item } & \multicolumn{6}{|c|}{ Nível de cálcio nas dietas (\%) } \\
\hline & 3,0 & 3,4 & 3,8 & 4,2 & 4,6 & 5,0 \\
\hline \multicolumn{7}{|l|}{ Ingrediente } \\
\hline Milho & 60,345 & 60,345 & 60,345 & 60,345 & 60,345 & 60,345 \\
\hline Farelo de soja & 21,770 & 21,770 & 21,770 & 21,770 & 21,770 & 21,770 \\
\hline Glúten de milho $60 \%$ & 2,182 & 2,182 & 2,182 & 2,182 & 2,182 & 2,182 \\
\hline Oleo de soja & 1,484 & 1,484 & 1,484 & 1,484 & 1,484 & 1,484 \\
\hline Fosfato bicálcico & 1,488 & 1,488 & 1,488 & 1,488 & 1,488 & 1,488 \\
\hline Calcário & 6,614 & 7,656 & 8,698 & 9,739 & 10,781 & 11,823 \\
\hline Sal & 0,576 & 0,576 & 0,576 & 0,576 & 0,576 & 0,576 \\
\hline L-lisina $\mathrm{HCl}$ & 0,003 & 0,003 & 0,003 & 0,003 & 0,003 & 0,003 \\
\hline Dl-metionina & 0,119 & 0,119 & 0,119 & 0,119 & 0,119 & 0,119 \\
\hline Cloreto de colina $(70 \%)$ & 0,100 & 0,100 & 0,100 & 0,100 & 0,100 & 0,100 \\
\hline Mistura mineral ${ }^{1}$ & 0,050 & 0,050 & 0,050 & 0,050 & 0,050 & 0,050 \\
\hline Mistura vitamínico ${ }^{2}$ & 0,050 & 0,050 & 0,050 & 0,050 & 0,050 & 0,050 \\
\hline Antioxidante ${ }^{3}$ & 0,010 & 0,010 & 0,010 & 0,010 & 0,010 & 0,010 \\
\hline Inerte $^{4}$ & 5,528 & 4,166 & 3,124 & 2,083 & 1,041 & 0,000 \\
\hline \multicolumn{7}{|c|}{ Composição nutricional calculada } \\
\hline $\mathrm{Ca}(\%)$ & 3,000 & 3,400 & 3,800 & 4,200 & 4,600 & 5,000 \\
\hline PB (\%) & 17,00 & 17,00 & 17,00 & 17,00 & 17,00 & 17,00 \\
\hline EM (kcal/kg) & 2800 & 2800 & 2800 & 2800 & 2800 & 2800 \\
\hline Lisina (\%) & 0,811 & 0,811 & 0,811 & 0,811 & 0,811 & 0,811 \\
\hline Metionina + cistina (\%) & 0,700 & 0,700 & 0,700 & 0,700 & 0,700 & 0,700 \\
\hline Metionina (\%) & 0,397 & 0,397 & 0,397 & 0,397 & 0,397 & 0,397 \\
\hline Treonina (\%) & 0,654 & 0,654 & 0,654 & 0,654 & 0,654 & 0,654 \\
\hline Triptofano (\%) & 0,186 & 0,186 & 0,186 & 0,186 & 0,186 & 0,186 \\
\hline P disponível (\%) & 0,375 & 0,375 & 0,375 & 0,375 & 0,375 & 0,375 \\
\hline Ácido linoléico (\%) & 2,118 & 2,118 & 2,118 & 2,118 & 2,118 & 2,118 \\
\hline
\end{tabular}

1,2 Premix vitamínico e mineral por kg de produto: vit. A - 10.000.000 UI; vit. D3 - 2.000.000 UI; vit. E - 30.000 UI; vit. B1 - 2 mg; vit. B6 - 3 mg; ácido pantotênico - 12 mg; biotina - 0,1 g; vit. K3 - 3 mg; ácido fólico - 1 mg; ácido nicotínico - 1 mg; vit. B12 - 0,015 mg; Se - 0,25 mg; Mn - 106 mg; Fe - 100 mg; Cu - 20 mg; Co - 2 mg; I - 2 mg; excipiente q.s.p. - 1.000 g; ${ }^{3}$ Baynox; ${ }^{4}$ Inerte. 
sem casca ou deformados e alguma outra anormalidade foram anotados em fichas apropriadas.

O delineamento utilizado foi o inteiramente casualizado, constituído de seis níveis de cálcio (3,0; 3,4; 3,8; 4,2; 4,6 e $5,0 \%$ ) e seis repetições de seis aves por parcela para cada período experimental. Avaliaram-se o consumo de ração (g/ave/dia), a conversão alimentar (kg/dúzia), a produção diária de ovos (\%/ave/dia), o peso médio dos ovos (g), a massa de ovo (g/ave/dia) e a conversão por massa de ovos $(\mathrm{kg} / \mathrm{kg})$.

Ao final de cada período experimental, avaliou-se a qualidade dos ovos quebrando-se cinco ovos de cada parcela. Cada ovo foi pesado individualmente para registro dos pesos de gema e albúmen. Em seguida, as cascas foram secas em estufas de secagem a $105^{\circ} \mathrm{C}$ por 3 horas e pesadas para determinação do peso e da porcentagem da casca. Os valores dos cinco ovos coletados por parcela foram transformados em valores médios por parcela.

As análises estatísticas das características avaliadas foram realizadas utilizando-se o pacote computacional SAEG - Sistema para Análises Estatísticas e Genéticas (UFV, 1999), enquanto as estimativas de exigência de cálcio foram estabelecidas por modelos de regressão linear e quadrático.

\section{Resultados e Discussão}

Os níveis de cálcio da dieta não tiveram efeito $(\mathrm{P}>0,05)$ sobre a produção de ovos, o peso médio dos ovos, o consumo de ração, a massa de ovo e a conversão por massa de ovo (Tabela 2). Os valores de consumo de ração e peso dos ovos obtidos neste estudo estão de acordo com os relatados por Kussakawa (1998) e Vargas Jr. et al. (2004), mas diferem dos resultados encontrados por Frost \& Roland (1991), que afirmaram que o aumento do consumo de alimento ocorre segundo o aumento do cálcio e fósforo na dieta.
Fraga (1994) observou que o fornecimento de rações com mais de $4 \%$ de cálcio para poedeiras pode ocasionar problemas de palatabilidade e interferência no consumo. Vicenzi (1996) também mencionou que o excesso de cálcio na ração pode provocar redução no consumo de ração em virtude da pior palatabilidade, além da incidência de excretas moles e de depósitos calcários na casca do ovo. No entanto, segundo Borges (1999), o consumo de ração pelas aves pode ser afetado pelo nível de cálcio na ração, que parece agir no hipotálamo, no entanto, não se conhece ainda a intensidade de sua ação, se direta ou indireta, pois o hipotálamo induz a liberação de norepinefrina, um mediador que atua no sistema nervoso central propiciando aumento no consumo de ração.

Os níveis de cálcio da ração não influenciaram a produção média de ovos, o que confirma os resultados obtidos por Oliveira et al. (2002) e Clunies et al. (1992), que trabalharam, respectivamente, com níveis de 2,8 a 4,4\% e 3,5 a 4,5\% de cálcio na ração. Nakajima (1993), por sua vez, obteve resultados contrários e demonstraram que as poedeiras podem tolerar níveis relativamente altos de cálcio (mais de 6 g/ave/ dia) e não sofrerem efeito adverso no desempenho produtivo.

A porcentagem de ovos defeituosos foi de 1,27; 1,02; 1,$32 ; 0,38 ; 1,25$ e 1,05\% para as rações com 3,0; 3,4; 3,8; 4,2; 4,6 e 5,0\% de cálcio, respectivamente (Tabela 3). A análise estatística desses resultados não permitiu ajuste de equação de regressão para esta variável. Segundo Hester (1999), se os ovos apresentam problemas com a qualidade da casca, o nível de cálcio deve ser aumentado em 1 g/ave/dia, de modo que não exceda $6 \mathrm{~g} / \mathrm{ave} / \mathrm{dia}$.

Houve efeito significativo $(\mathrm{P}<0,05)$ dos níveis de cálcio na ração sobre o peso da casca (Figura 1). O melhor resultado foi obtido com 4,3\% de cálcio, próximo da exigência preconizada por Rostagno et al. (2000), de 4,2\%, para poedeiras semipesadas. $\mathrm{O}$ cálcio da dieta é absorvido no trato gastrintestinal das aves e utilizado para a formação da

Tabela 2 - Desempenho produtivo de aves semipesadas após o pico de postura alimentadas com rações com seis níveis de cálcio

\begin{tabular}{|c|c|c|c|c|c|}
\hline Nível de cálcio (\%) & $\begin{array}{l}\text { Produção de } \\
\text { ovos (\%) }\end{array}$ & $\begin{array}{l}\text { Peso dos } \\
\text { ovos (g) }\end{array}$ & $\begin{array}{l}\text { Consumo de ração } \\
\text { (g/ave/dia) }\end{array}$ & $\begin{array}{l}\text { Massa de } \\
\text { ovo (g) }\end{array}$ & $\begin{array}{c}\text { Conversão por massa } \\
\text { de ovo }(\mathrm{kg} / \mathrm{kg})\end{array}$ \\
\hline 3,0 & 85,74 & 65,56 & 126,17 & 56,20 & 2,29 \\
\hline 4,2 & 87,85 & 65,93 & 124,83 & 57,90 & 2,26 \\
\hline 4,6 & 87,83 & 65,56 & 127,63 & 57,62 & 2,24 \\
\hline 5,0 & 85,42 & 65,63 & 125,94 & 56,05 & 2,27 \\
\hline Regressão & ns & ns & ns & ns & ns \\
\hline CV (\%) & 4,63 & 2,41 & 2,07 & 5,05 & 8,21 \\
\hline
\end{tabular}

ns - não-significativo. 
Tabela 3 - Características dos ovos de poedeiras semipesadas após o pico de postura alimentadas com rações com seis níveis de cálcio

\begin{tabular}{|c|c|c|c|c|c|c|}
\hline Nível de cálcio (\%) & Peso do albúmen (g) & Peso da gema (g) & Peso da casca (g) & Albúmen (\%) & Gema (\%) & Casca $(\%)$ \\
\hline 3,0 & 41,45 & 17,72 & 6,13 & 63,48 & 27,13 & 9,39 \\
\hline 3,4 & 42,21 & 18,38 & 6,44 & 62,97 & 27,42 & 9,61 \\
\hline 3,8 & 41,86 & 18,56 & 6,46 & 62,57 & 27,77 & 9,66 \\
\hline 4,6 & 40,85 & 18,64 & 6,40 & 61,99 & 28,29 & 9,71 \\
\hline 5,0 & 41,09 & 18,31 & 6,46 & 62,41 & 27,79 & 9,80 \\
\hline CV (\%) & 3,59 & 3,99 & 3,21 & 1,83 & 3,98 & 3,09 \\
\hline
\end{tabular}

ns - não-significativo.

$\mathrm{Q}^{*}$ - efeito quadrático a $5 \%$ de probabilidade.

$\mathrm{L}^{*}$ - efeito linear a $5 \%$ de probabilidade.
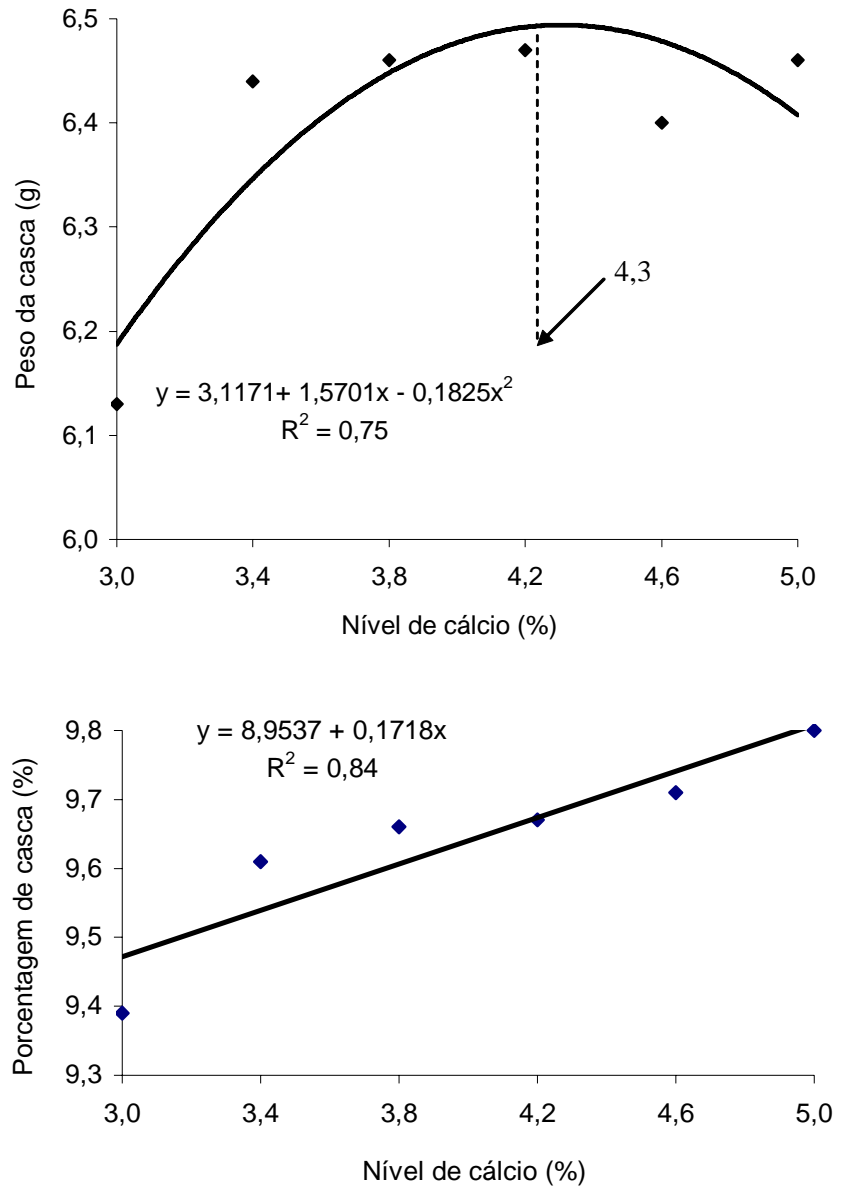

Figura 1 - Peso da casca e porcentagem de casca do ovo de poedeiras semipesadas após o pico de postura alimentadas com rações com seis níveis de cálcio.

casca e para as funções vitais do organismo. Esse cálcio é aproveitado em quantidade suficiente para que a ave mantenha suas atividades metabólicas. O excesso, no entanto, interfere na disponibilidade de outros minerais, como fósforo, magnésio, manganês e zinco, e dilui outros componentes, além de tornar a dieta menos palatável.
Os níveis de cálcio dietético tiveram efeito linear decrescente sobre a porcentagem de albúmen. Entretanto, o coeficiente de determinação da equação de regressão foi relativamente baixo $\left(\mathrm{r}^{2}=0,56\right)$. Resultados de estudos sobre efeitos do cálcio no desempenho e na qualidade dos ovos relacionam os níveis de cálcio à produção e ao peso dos ovos, à espessura, ao peso e à porcentagem da casca e à gravidade específica, mas não fornecem quaisquer informações sobre a influência desse mineral sobre o peso e a porcentagem de albúmen e gema (Castillo et al., 2004; Jardim Filho et al., 2005; Hernández-Sánchez et al., 2006).

A porcentagem de casca aumentou de forma linear $(\mathrm{P}<0,05)$ de acordo com o nível de cálcio da ração (Figura 1). Segundo Frost \& Roland (1991), o aumento do nível de cálcio melhora a resistência da tíbia, o valor de cinza nos ossos e a concentração iônica plasmática. Como é um nutriente que tem como função primordial nas poedeiras a formação da casca do ovo, o aumento do nível dietético desse mineral promove maior desenvolvimento da casca em relação aos demais componentes do ovo (albúmen e gema).

\section{Conclusões}

Sugere-se utilizar no mínimo 4,3\% de cálcio em rações para poedeiras semipesadas após o pico de postura.

\section{Literatura Citada}

BAR, A.; RAZAPHKOVSKY, V.; VAX, E. Re-evaluation of calcium and phosphorus requirements in aged laying hens. British Poultry Science, v.43, n.2, p.261-269, 2002.

BERTECHINI, A.G. Nutrição de monogástricos. Lavras: Faepe, 1998. 273p.

BORGES, A.L.C.C. Controle da ingestão de alimentos. Cadernos Técnicos da Escola de Veterinária da UFMG, v.27, p.6779, 1999.

CASTILLO, C.; CUCA, M.; PRO, A. et al. Biological and economic optimum level of calcium in white leghorn laying hens. Poultry Science, v.83, p.868-872, 2004. 
CLUNIES, M.; ENSLIE, J.; LEESON, S. Calcium and phosphorus metabolism and eggshell formation of hens fed with different amounts of calcium. Poultry Science, v.71, n.3, p.482-489, 1992.

FROST, T.I.; ROLAND SR, D.A. The influence of various calcium and phosphorus levels on tibia strength and eggshell quality of pullets during peak production. Poultry Science, v.70, p.963, 1991.

HERNÁNDEZ-SÁNCHEZ, J.; CUCA-GARCÍA, M.; PRÓ-MARTÍNEZ, A. et al. Nivel óptimo biológico y económico de calcio en gallinas Leghorn blancas de segundo ciclo de postura biological and economic optimum level of calcium in white leghorn of second cycle laying hens. Agrociência, v.40, n.1, 2006.

HESTER, P.Y. A qualidade da casca do ovo. Avicultura Industrial, n.1072, p.20-30, 1999.

HUNTON, P. Pesquisas sobre a estrutura e a qualidade da casca do ovo: um histórico. In: CONFERÊNCIA APINCO 2004 DE CIÊNCIA E TECNOLOGIAS AVÍCOLAS. Santos, 2004. Anais... Santos: Fundação Apinco de Ciência e Tecnologia Avícolas, 2004. v.2, p.21-24.

JARDIM FILHO, R.M.; STRINGHINI, J.H.; CAFÉ, M.B. et al. Influência das fontes e granulometria do calcário calcítico sobre desempenho e a qualidade da casca dos ovos de poedeiras comerciais. Acta Scientiarum, v.27, n.1, p.35-41, 2005.

KUSSAKAWA, K.C.K.; MURAKAMI, A.E.; FURLAN, A.C. Combinações de fontes de cálcio em rações de poedeiras na fase final de produção e após muda forçada. Revista Brasileira de Zootecnia, v.27, n.3, p.572-578, 1998.

LEESON, S.; SUMMERS, J.D. Dietary salt for layers. Nutrition reports international, v.19, n.2, p.173-179, 1979.

OLIVEIRA, J.R.; BERTECHINI, A.G.; FASSANI, E.J. et al. Níveis de cálcio em dietas para poedeiras leves e semipesadas no segundo ciclo de produção. Revista Ciência e Agrotecnologia, v.26, n.5, p.1060-1067, 2002.

RODRIGUES, E.A.; JUNQUEIRA, O.M.; VALÉRIO, M. et al. Níveis de cálcio em rações de poedeiras comerciais no segundo ciclo de postura. Acta Scientiarum, v.27, n.1, p.49-54, 2005.

ROSTAGNO, H.S.; SILVA, D.J.; COSTA, P.M.A. et al. Composição de alimentos e exigências nutricionais de aves e suínos (Tabelas brasileiras). Viçosa, MG: Universidade Federal de Viçosa, 2000. 141p.

SCOTT, M.L.; NESHEIM, M.C.; YOUNG, R.J. Nutrition of the chickens. 3.ed. New York: Ithaca, 1982. 562p.

UNIVERSIDADE FEDERAL DE VIÇOSA - UFV. Manual de utilização do programa SAEG - Sistema de análise estatística e genética. Viçosa, MG: Universidade Federal de Viçosa, 1999, 59p.

VICENZI, E. Fadiga de gaiola e qualidade da casca do ovo - aspectos nutricionais. In: SIMPÓSIO TÉCNICO DE PRODUÇÃO DE OVOS, 6., 1996, São Paulo. Anais... São Paulo: Associação Paulista de Avicultura, 1996. p.77-91. 